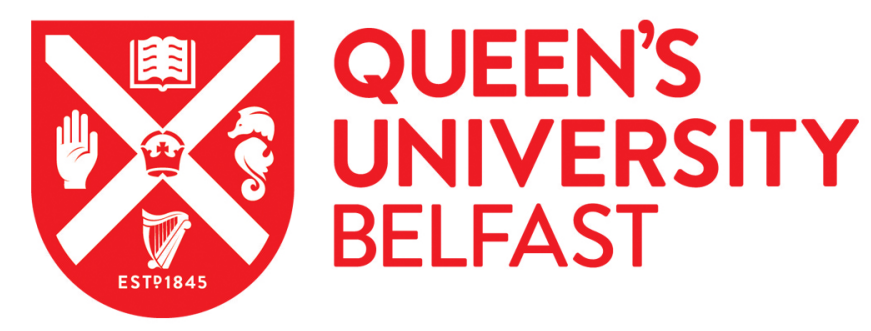

\title{
Ethical issues experienced during palliative care provision in nursing homes
}

Muldrew (Née Preshaw), D. H. L., McLaughlin, D., \& Brazil, K. (2018). Ethical issues experienced during palliative care provision in nursing homes. Nursing Ethics. https://doi.org/10.1177/0969733018779218

\section{Published in:}

Nursing Ethics

\section{Document Version:}

Peer reviewed version

Queen's University Belfast - Research Portal:

Link to publication record in Queen's University Belfast Research Portal

\section{Publisher rights}

(c) 2018 The Authors. This work is made available online in accordance with the publisher's policies. Please refer to any applicable terms of use of the publisher.

\section{General rights}

Copyright for the publications made accessible via the Queen's University Belfast Research Portal is retained by the author(s) and / or other copyright owners and it is a condition of accessing these publications that users recognise and abide by the legal requirements associated with these rights.

Take down policy

The Research Portal is Queen's institutional repository that provides access to Queen's research output. Every effort has been made to ensure that content in the Research Portal does not infringe any person's rights, or applicable UK laws. If you discover content in the Research Portal that you believe breaches copyright or violates any law, please contact openaccess@qub.ac.uk. 


\section{ETHICAL ISSUES EXPERIENCED DURING PALLIATIVE CARE PROVISION IN NURSING HOMES}

Deborah H.L. Muldrew (née Preshaw)

Ulster University, UK

Dorry McLaughlin and Kevin Brazil

Queen's University Belfast, UK

\section{ABSTRACT}

Background: Palliative care is acknowledged as an appropriate approach to support older people in nursing homes. Ethical issues arise from many aspects of palliative care provision in nursing homes, however, they have not been investigated in this context.

Aim: To explore the ethical issues associated with palliative care in nursing homes in the United Kingdom (UK).

Design: Exploratory, sequential, mixed methods design.

Methods: Semi-structured interviews with 13 Registered Nurses (RNs) and ten Healthcare Assistants (HCAs) working in 13 nursing homes in the UK were used to explore ethical issues in palliative care. The "Ethical Issues in Palliative Care for Nursing Homes" instrument was used to measure the frequency and level of distress of ethical issues through a cross-sectional survey with $69 \mathrm{RNs}$ and 129 HCAs. Data collection occurred between December 2014 and November 2015.

Ethics: Ethical approval was granted by Queen's University's School of Nursing and Midwifery Research Ethics Committee and governance sought from each nursing home's manager.

Findings: The interviews revealed three themes: ethical issues in practice; relational issues; and organisational issues. No significant differences between RNs and HCAs were evident, confirming the patterns emerging from the interviews. 
Relational issues, primarily issues with residents and families, occurred most frequently and caused greater distress.

Conclusion: The shared environment is key in the experience of ethical issues; therefore, multidisciplinary education is needed for ethical decision making in palliative care. Addressing staff knowledge and service organisation may reduce ethical issues locally, and provide a benchmark for global change.

KEYWORDS: Palliative care, Care Homes, Nursing homes, Ethics, Adult Nursing, Healthcare Assistants, Mixed methods

\section{INTRODUCTION}

The population of older adults is increasing more rapidly than the total population on a global scale, with most significant increases evident in Europe (1). Within the United Kingdom, $40 \%$ of the population aged 65 and over have a chronic illness, and this increases to $69 \%$ in the population aged 85 and over (2). More older people are living and dying in nursing homes. Between 2006 and 2008, just $12.1 \%$ of people died in nursing homes (3), compared with $20 \%$ in 2015 (4). The trend of an ageing population is one that will continue and, due to the increased prevalence of chronic illness and complex co-morbidities, result in increased pressure on resources in nursing homes (5).

Generalist palliative care is acknowledged as an appropriate approach to support older people in nursing homes, with referral to external specialist palliative care when appropriate $(6,7)$. Palliative care is defined as "an approach that improves the quality of life of patients and their families facing the problem associated with life- 
threatening illness, through the prevention and relief of suffering by means of early identification and impeccable assessment and treatment of pain and other problems, physical, psychosocial and spiritual" (8). A topic review found that ethical issues in palliative care primarily arise from the legalities of end of life care, advance care planning, inappropriate use of medical interventions, and symptom specific issues (9). Research by Lillemoen (10) showed that healthcare providers with the most frequent contact with residents receiving palliative care were more likely to experience more ethical issues, therefore, registered nurses (RNs) and healthcare assistants (HCAs) are an important target audience for research into ethical issues. The ethical issues reported in the international nursing home literature (11) may also be relevant to palliative care provision, including conflicting professional ethical principles, communication breakdown leading to relational ethical issues, and organisational ethical issues including lack of resources and quality of care provision, however, this has yet to be researched.

\section{AIM}

This research aimed to provide a comprehensive understanding of the care provider's experiences of ethical issues during palliative care provision within nursing homes in the United Kingdom.

\section{METHODS}

\section{Design}

A two phase, exploratory, sequential, mixed-methods design based on the taxonomy of Creswell and Plano- Clark (12) was identified as the most appropriate design to fully address the research aim. Insufficient prior research was available to justify an explanatory design, therefore, it would be inappropriate to conduct the quantitative research first. Additionally, the information gained from the qualitative exploration was 
used to shape the quantitative survey, and therefore the two methods could not run in parallel. The first phase focused on RN and HCA experiences of ethical issues and the second phase focused on understanding the frequency and level of distress reported by RNs and HCAs associated with these issues across Northern Ireland. Data collection for Phases 1 and 2 occurred between December 2014 and November 2015.

\section{FIGURE 1 HERE}

\section{$\underline{\text { Participants }}$}

In Phase 1, semi-structured interviews were undertaken with purposive sample of RNs and HCAs from 13 nursing homes across Northern Ireland who accepted an invitation to participate. Staff were recruited through the provision of an information pack and oral presentation about the study by the researcher. If they were willing to participate, they completed the consent form and the researcher contacted them directly using the provided contact information. Participants were recruited until saturation was reached and no new themes were emerging from the dataset, which was anticipated to be approximately 12 interviews based on the research literature (13).

In Phase 2, a cross-sectional survey was conducted with all RNs and HCAs employed in 18 nursing homes across Northern Ireland who were working on the day of data collection. Based on feedback from Phase 1, the researcher recruited in person at the nursing homes at arranged times, and staff were invited to participate. In the United Kingdom, no data was available to indicate the total number of RNs and HCAs employed in nursing homes, therefore, a power calculation was not possible. To allow for an exploratory factor analysis (EFA) which was conducted as part of the larger study, Costello and Osbourne (14) recommend a sample size of 
200. To ensure safe staffing levels, the Regulation and Quality Improvement Authority (15) recommend a ratio of $35 \%$ RNs to $65 \%$ HCAs, therefore, 70 RNs and 130 HCAs was the desired sample size. A convenience sample of 23 nursing homes were approached, and 18 responded positively to an invitation to partake. The total number of RNs and HCAs employed per home ranged from nine to 100 (Mean=33.2, Standard Deviation $(S D)=24.4)$.

In both Phases, the inclusion criteria were as follows: currently employed in the nursing home as an RN or HCA; over 18 years old; and could provide informed consent.

\section{Data collection}

In Phase 1, qualitative, audio-recorded semi-structured interviews using the critical incident technique (16) were used to ascertain the key ethical issues surrounding palliative care provision within the nursing home setting. An interview guide was developed based on a previous study (17) and pilot tested prior to use. Each participant undertook one interview. Individual interviews were held in a private room within the nursing home, and lasted from 11 to 67 minutes (median $=30$ minutes).

In Phase 2, a cross-sectional survey was used to assess the frequency of, and level of distress experienced by RNs and HCAs associated with ethical issues during palliative care provision in the nursing home. The survey was undertaken within the nursing home in which they were employed, located across Northern Ireland. Participants completed the surveys during their shift and returned them to the collection point on the same day.

The "Ethical issues in palliative care for nursing homes" (EPiCNH) (18) was used to collect data. The survey was developed through a literature review, interviews with key stakeholders to develop items, face validity testing with an expert panel and pilot 
testing with the population of interest. The scale consisted of 26 items, scored on two subscales; the Frequency Scale and the Distress Scale (Further details on the psychometric properties of the instrument have been previously published (18)). Participants were asked to rate each item from 0 to 4 , with a score of 0 indicating the item did not occur frequently or cause any level of distress, and a score of 4 indicating high frequency or high distress.

\section{Analysis of Data}

Phase 1 data were stored and managed through NVivo 10 software. And $10 \%$ of audio recordings and transcripts were independently reviewed and analysed by the research team to ensure transcript accuracy and to increase credibility of the interpretation. Interviews were transcribed verbatim and analysed concurrently through Thematic Analysis (19). This included a six-step process of familiarisation, generating codes, searching for themes, reviewing themes, defining and naming themes, and producing a report.

Survey data (anonymised) was entered and managed using IBM SPSS Statistics v22. Ten percent were checked for transcription errors by a member of the research team (DMcL). Descriptive statistics were used in phase two to summarise what was revealed through the survey and highlight which themes were most prevalent. T-tests were conducted to look for similarities and differences between RNs and HCAs in terms of both frequency and distress.

Validity and reliability: Lincoln and Guba's (20) framework for trustworthiness and rigour was used to assess credibility. Member checking was conducted to confirm credibility, a thick description was used to improve transferability, dependability was assessed by external audits, and reflexivity through a reflexive journal allowed for 
confirmability of findings. Each team member independently analyses the transcripts then discussed and agreed codes to confirm inter-rater reliability.

\section{$\underline{\text { Integration }}$}

Following the guidance of Creswell and Plano Clark (2011), integration was undertaken through data transformation and a spiralled comparison within the discussion. The data from Phase 1 was integrated with the literature review and informed the development of the survey instrument utilised in Phase 2. Phase 1 categories linked to items in the survey which allowed the items to be ranked in terms of frequency of occurrence and level of distress associated with the theme. Results were presented in a spiralled comparison, which means data from Phase 1 and 2 are integrated and then described concurrently.

\section{Ethical approval}

Ethical approval was granted by Queen's University's School of Nursing and Midwifery Research Ethics Committee (02.DPreshaw.08.15.M7.V4). All participants were supplied with a participant information sheet which discussed confidentiality, anonymity, disclosure of sensitive information, and participant welfare. Written informed was obtained prior to participation in the interviews, whereas consent was implied based on the return of the survey. Governance was sought from the manager of each nursing home.

\section{RESULTS}

\section{Participant Profile}

Table 1 portrays the demographic characteristics of the sample who completed the survey, including their work designation, age, gender, education, and number of years spent within the nursing home.

\section{TABLE 1 HERE}


Main Findings

The interviews revealed three themes related to ethical issues reported by healthcare providers during palliative care provision; "Ethical issues in practice," "Relational ethical issues," and "Organisational ethical issues". Data from the two phases have been presented in a spiralled comparison (Table 2).

\section{TABLE 2 HERE}

\section{Ethical issues in practice}

Ethical issues in practice were found when participants experienced conflict between what they felt was right and what was their duty of care. This included respecting human rights, conflicting bioethical principles (autonomy, beneficence, nonmaleficence, and justice) and nursing ethical principles (fairness, respect of dignity, and truthfulness, issues with autonomy due to a lack of advance care planning, and the use of futile or aggressive treatment. The quotes below demonstrate the challenges in being truthful, and conflicting ethical principles of resident autonomy and beneficence:

"I'm a nurse so I shouldn't lie to my resident ... but sometimes it's very difficult" (Participant O, RN, p4)

"you do feel you're going against their wish but at the same time, you need to get washed ... or you need to eat, you're only trying to encourage something for your own good ... but you do feel uncomfortable doing it" (Participant L, HCA, p5)

The survey revealed that items associated with issues in practice were generally found to occur less frequently than items associated with the other themes. The only item within this theme to occur frequently related to decision making on the 
resident's behalf to prevent them from coming to harm $(M=2.68 ; S D=1.24)$. These items were also associated with lower levels of distress (Table 2).

\section{Relational ethics}

Relational issues focused on the conflicts within the relationships of staff, families, and residents including attentiveness to resident care needs, responsiveness to criticism and demands from families and care partners, and concerns about the competence of colleagues. The following quotes demonstrate specific examples of conflict with families over the best interests of the resident, and concerns over the compassion of a colleague:

\section{"I had a family and the mother's 91, she has dementia and they} insisted she was taken off her night sedation with the result of the woman didn't sleep and was up all night shouting" (Participant B,

$$
R N, p 8)
$$

\section{“I think her [the nurse's] manner was sharp and maybe not as}

sympathetic as she should have been" (Participant A, RN, p12)

The resident's refusal of food and fluids was reported to occur most frequently out of all the survey items $(M=2.71 ; S D=1.19)$, which linked to attentiveness to residents care needs. Witnessing distress from family and care partners was the third most frequently reported item $(M=2.27 ; S D=1.17)$, and following the family's care wishes against their personal opinion was the fourth most frequently reported item $(M=2.03$; $S D=1.26)$. These scores on the survey highlight relational ethical issues as the most frequently occurring of the three themes. These items were also found within the top five items on the Distress Scale of the survey (Table 2). 


\section{Organisational ethics}

Organisational issues were a consequence of the structure and quality of services available within the nursing home and included distributive justice (resource allocation and quality of services), the organization of services, particularly the coordination with, and responsiveness of, locum GPs, , and staff wellbeing. The quotes below demonstrate the personal struggle with lack of time to get to know the residents, and the quality of services to ensure residents feel like a person and not a number:

"Sitting with someone and having a chat goes a long way ... you just don't have that time since coming here" (Participant M, RN, p5)

“I don't believe somebody should feel like a number on a door and to me ... that's the way people are" (Participant L, HCA, p7)

Organisational ethical issues, particularly lack of resources, were found to cause higher levels of distress for participants for example, lack of time $(M=2.36 ; S D=1.44)$, professional incompetence due to lack of staff training $(M=2.17 ; S D=1.48)$, and involvement in non-care activities which reduce time spent with the residents $(M=$ 1.90; $S D=1.48)$. These items were all scored moderately on the frequency score, with mean scores from 1.49 to 1.77 . However, ethical issues associated with service quality were seen to occur infrequently and cause the least amount of distress (Table 2).

\section{$\underline{\text { Integration of datasets }}$}

The data from Phase 1 and 2 were integrated and presented in a spiralled comparison to draw out three key findings. Firstly, relational ethical issues are most distressing to healthcare providers when providing palliative care. Elements include 
attentiveness, responsibility, competence, and responsiveness, and how these can conflict during daily palliative care provision. Examples of this finding include: interactions between RNs and HCAs and the families of patients receiving palliative care resulted in frequent ethical issues and a high level of distress; resistance from residents during care provision was very distressing for most healthcare providers; and poor communication between staff was both frequent and distressing. Secondly, staff training in palliative care is still lacking, but desired by healthcare providers to improve experiences of palliative care provision and reduce ethical issues. Finally, communication to facilitate shared decision making between families and the multidisciplinary team is essential to improve palliative care and reduce ethical issues.

\section{DISCUSSION}

The aim of this research was to provide a comprehensive understanding of care providers' experiences of ethical issues during palliative care provision within nursing homes. The interviews revealed three main themes in which ethical issues could be categorised: ethical issues in practice; relational issues; and organisational issues. The EPiCNH survey identified relational ethical issues to be the most frequently occurring, and the most distressing, ethical issues reported by RNs and HCAs. No significant differences between the RN and HCA survey data were evident in both the Frequency Scale and Distress Scale, which confirmed the patterns emerging from the qualitative interviews. Synthesizing the findings from Phase 1 and 2 revealed that the theme of relational issues, primarily issues with residents and issues with families, was most likely to occur frequently and cause higher levels of distress. 


\section{Interpretation of Main Findings}

Decision-making to ensure fair and ethical treatment, balancing autonomy, justice, and non-maleficence, and effective communication to support beneficent care were the most frequently raised issues in practice, highlighting the need to address these areas directly through improved training. Managing challenging behaviour and negative symptoms, particularly in terms of resisting care, was a clear example of the struggle between balancing justice and non-maleficence. It is supported throughout previous studies, for example, Gjerberg et al (21) found RNs and auxiliary nurses to report ethical dilemmas due to demanding residents who ended up with more resources and breaches in patient autonomy. The conflicting ethical principles of beneficence and autonomy were commonly cited throughout the literature (22-24), for example, disagreements between nurses and patients were reported when the best patient outcomes were limited by the patient's wishes. The current research has added to the knowledge base by demonstrating how communication challenges can lead to ethical issues irrespective of the capacity of the resident.

Relational issues were found to be most frequent and most distressing, setting apart palliative care ethical issues from ethical issues experienced during everyday nursing care. This research added to the evidence base by demonstrating how a lack of family understanding can lead to unrealistic demands within palliative care, however, while openness with the family is important, the resident must remain central to the decision making process. The influence of family distress on care may suggest a need to include families actively in decision-making processes from the beginning of the care journey. Interacting with family members was found to be a concern for RNs and HCAs in both this study and many previous studies including by 
Enes and DeVries (25), Schaffer (26) and Gjerberg et al (27). These studies found meeting relative's needs, interacting with families, communicating about death, and disagreements over treatment to be major ethical issues. Lopez $(28,29)$ identified nurses as feeling "in the middle," of decision making processes and ambiguous in terms of their specific role as they wished to create a plan that was acceptable to the GP, the family, and the patient. Trying to satisfy everyone within the decision making process was identified by nurses as a concern in the current study, however, HCAs previously reported getting on with the job instead of involving themselves in decision making (30).

Lack of staff and problems with GP involvement were highlighted as the main organisational ethical issues, indicating a need to increase resources and improve coordination of GP care within nursing homes. Many issues involving the GP were reported within the literature. Dreyer et al (31) found that homes with only one GP visit per week also had limited coordination of care, and Enes and DeVries (25) found lack of GP knowledge of symptom control to be an ethical issue. Involving GPs in nursing home care proved challenging for participants both in the current study and in Schaffer's (26) study, where difficulty contacting GPs was one of the most frequently occurring ethical problems. While restraint was commonly found as an ethical issue throughout the literature (11), it was not identified by participants in the current research. This could be caused by a lack of understanding of restraint and how it may conflict with a person's right to freedom, or it could be a result of better management and use of restraint.

\section{Strengths and Limitations}

The main strengths of this research include: the rigorous pilot testing of the interview schedule and the survey instrument prior to use; team collaboration throughout the 
analysis process; and the practical element of a mixed methods approach which resulted in clear and direct messages for service improvement. Limitations have also been recognised. This study was only conducted in one part of the UK, limiting its wider application. The challenges of researching ethical issues which have previously been poorly defined, and the recognition that nursing homes who are willing to participate in research may be systematically different to those who are unwilling to participate in research may limit the applicability of findings across all nursing homes.

\section{What this paper adds}

Key implications for policy include the need for inclusion of ethical decision-making within palliative care education, and support for the UK Clinical Ethics Network's (UKCEN's) argument (32) that it is time for formal recognition of clinical ethical committees, with the services of such committees made available to nursing homes. This recommendation has global implications for palliative care provision, linking to the World Health Organization's (WHO) acknowledgement of the need for training and debate on the ethical aspects of a range of issues for those receiving palliative care (33).

The overwhelming similarities between RNs and HCAs highlights the importance of the shared environment in the experience of ethical issues. The key implications for practice include the need for multidisciplinary training and support for RNs and HCAs who are struggling to build strong networks with residents, families, or colleagues, and a means of incentivising training in palliative care to help overcome common ethical issues. Training staff to take account of patient and family values and incorporate this into decision making has been recognised by the WHO as a means of addressing important ethical issues (33). Distribution of knowledge in ethical

\section{VERSION 2}


decision making in palliative care may be achieved by support of local knowledge transfer projects which are low cost to run and accessible remotely, for example, Project Extension for Community Health Outcomes (ECHO). ECHO is an evidencebased tele-mentoring intervention that connects primary care providers with expert teams of specialist providers via regularly scheduled videoconference (34) Additionally, the implementation of strategies to strengthen and organise services, access, and referral systems that are fully integrated across healthcare delivery would address many sources of ethical issues raised in this research.

Future research may consider exploring how to develop a multidisciplinary approach to palliative care education and ethical decision making, why training in palliative care is unattended, and evaluating patterns of usage to search for methods of improving attendance. Additionally, researchers should seek to understand the family's perspective when engaging with nursing homes, including the development of family friendly strategies to increase the likelihood of families engaging in care decisions.

\section{CONCLUSION}

This research has identified the ethical issues reported by RNs and HCAs during palliative care provision in the nursing home. Relational ethical issues were most distressing to healthcare providers when providing palliative care, in particular, poor staff communication and its impact on the quality of care for residents. The shared environment is key in the experience of ethical issues; therefore, multidisciplinary education, with managerial support, is needed for ethical decision making in palliative care. Addressing staff knowledge links to global policies on training in ethical debate for palliative care, and may be achieved by transferring knowledge and specialist skills through mechanisms such as Project ECHO. Integration of 
nursing home services with specialist palliative care services should be a priority for research and policymaking nationally and internationally, due to its impact on ethical issues and quality of care provision.

\section{DECLARATIONS}

Authorship: DP, DM, and KB made a substantial contribution to the design of the work, the acquisition, analysis, and interpretation of data, revised the manuscript, and approved the final version to be published.

Funding: This research was funded by a student scholarship from Queen's University, Belfast

Supplementary Materials: Additional information relating to the project can be accessed by contacting the corresponding author

Conflict of interest: The authors declare no conflict of interest 


\section{REFERENCES}

1. United Nations. World Population Ageing: 1950-2050 [Internet]. New York: NY; 2001. Available from: http://www.un.org/esa/population/publications/worldageing19502050/

2. Age UK. Later Life in the United Kingdom [Internet]. Age UK; 2017. Available from: https://www.ageuk.org.uk/Documents/ENGB/Factsheets/Later_Life_UK_factsheet.pdf?dtrk=true

3. National end of life care Intelligence Network. Deaths in Older Adults in England. 2010, United Kingdom.

4. Northern Ireland Statistics and Research Agency. Registrar General Northern Ireland: Annual report 2015 [Internet]. 2016 [cited 2017 May 29]. Available from: http://www.nisra.gov.uk

5. Royal College of Nursing. Care homes under pressure - an England report. 2010;(April):0-18.

6. Reitinger E, Froggatt K, Brazil K, Heimerl K, Hockley J, Kunz R, et al. Palliative Care in Long-term Care Settings for Older People: findings from an EAPC Taskforce. Eur J Palliat Care. 2013;20(5):251-3.

7. Guidelines and Audit Implementation Network. Guidelines for Palliative and End of Life Care in Nursing Homes and Residential Care Homes [Internet]. 2013. Available from: http://www.hscbereavementnetwork.hscni.net/wpcontent/uploads/2015/05/GAIN-Guidelines-for-Palliative-and-End-of-Life-Carein-Nursing-Homes-Residential-Care-Homes-Appendix-2-Revised-September2014.pdf

8. World Health Organisation. National Cancer Control Programmes: Policies and Managerial Guidelines - 2nd ed. Geneva; 2002.

9. Fromme EK, Smith MS. Ethical Issues in Palliative Care [Internet]. UpToDate. 2016 [cited 2017 May 26]. Available from: https://www.uptodate.com/contents/ethical-issues-in-palliative-care

10. Lillemoen L, Pedersen R. Ethical challenges and how to develop ethics support in primary health care. Nurs Ethics. 2013 Feb;20(1):96-108.

11. Preshaw DHL, Brazil K, Mclaughlin D. Ethical issues experienced by healthcare workers in nursing homes : Literature review. Nurs Ethics. 2015;

12. Creswell JW, Plano Clark VL. Designing and Conducting Mixed Methods Research. 2nd ed. Thousand Oaks CA: Sage Publications, Inc; 2011. 53-106 p.

13. Guest G, Bunce A, Johnson L. How Many Interviews Are Enough? An Experiment with Data Saturation and Variability. Fam Heal Int. 2006;18(1):59_ 82.

14. Costello A, Osborne J. Best practices in exploratory factor analysis: four recommendations for getting the most from your analysis. Pract Assessment, Res Eval. 2005;10(7). 
15. The Regulation and Quality Improvement Authority. The Development of a Staffing model for Nursing Homes - Staffing Guidelines for Nursing Homes [Internet]. $2009 . \quad$ Available from: www.rqia.org.uk/RQIA/media/RQIA/Resources/Standards/nursing_homes_sta ndards_-_april_2015.pdf

16. Flanagan JC. The critical incident technique. Psychol Bull. 1954 Jul;51(4):32758.

17. Brazil K, Kassalainen S, Ploeg J, Marshall D. Moral distress experienced by health care professionals who provide home-based palliative care. Soc Sci Med. 2010 Nov;71(9):1687-91.

18. Preshaw DHL, Mclaughlin D, Brazil K. Ethical issues in palliative care for nursing homes: development and testing of a survey instrument. J Clin Nurs [Internet]. 2017 Oct 20 [cited 2017 Nov 10]; Available from: http://doi.wiley.com/10.1111/jocn.14118

19. Braun V, Clarke V. Using Thematic Analysis in Psychology. Qual Res Psychol. 2006;3(2):77-101.

20. Lincoln Y, Guba E. Naturalistic Inquiry. Newbury Park: CA: Sage Publications; 1985.

21. Gjerberg E, Førde R, Pedersen R, Bollig G. Ethical challenges in the provision of end-of-life care in Norwegian nursing homes. Soc Sci Med. 2010 Aug;71(4):677-84.

22. Linzer N, Samuel J, Sable J. Judaism, professional intervention, and ethics in long-term care. J Pastoral Care. 2000;54(1):33-43.

23. Powers BA. Ethnographic Analysis of Everyday Ethics in the Care of Nursing Home Residents With Dementia: A Taxonomy. Nurs Res. 2001;50(6):332-9.

24. Slettebo A, Bunch EH. Ethics in Nursing Homes: Experience and Casuistry. Int J Nurs Pract. 2004;10:159-65.

25. Enes SPD, de Vries K. A survey of ethical issues experienced by nurses caring for terminally ill elderly people. Nurs Ethics. 2004 Mar;11(2):150-64.

26. Schaffer MA. Ethical Problems in End-of-Life Decisions for Elderly Norwegians. Nurs Ethics. 2007 Mar;14(2):242-57.

27. Gjerberg E, Førde R, Bjørndal A. Staff and family relationships in end-of-life nursing home care. Nurs Ethics. 2011;18(1):42-53.

28. Lopez RP. Decision-making for acutely ill nursing home residents: nurses in the middle. J Adv Nurs. 2009 May;65(5):1001-9.

29. Lopez RP, Amella EJ, Mitchell SL, Strumpf NE. Nurses' perspectives on feeding decisions for nursing home residents with advanced dementia. J Clin Nurs. 2010;19(5/6):632-8.

30. McClement S, Lobchuk M, Chochinov HM, Dean R. "Broken covenant": healthcare aides' "experience of the ethical" in caring for dying seniors in a personal care home. J Clin Ethics. 2010 Jan;21(3):201-11. 
31. Dreyer A, Forde R, Nortvedt P. Ethical decision-making in nursing homes: Influence of organizational factors. Nurs Ethics [Internet]. 2011 Jul 1 [cited 2017 May 29];18(4):514-25. Available from: http://www.ncbi.nlm.nih.gov/pubmed/21673118

32. UK Clinical Ethics Network. Recognising, preventing and resolving ethical dilemmas in health care: the need for clinical ethics support in the NHS [Internet]. $2015 . \quad$ Available from: http://www.ukcen.net/index.php/main/whats_new/recognising_preventing_and _resolving_ethical_dilemmas_in_health_care

33. World Health Organization. PALLIATIVE CARE THE SOLID FACTS [Internet]. 2004 [cited 2017 Nov 10]. Available from: http://www.euro.who.int/_data/assets/pdf_file/0003/98418/E82931.pdf

34. Arora S, Kalishman S, Dion D, Som D, Thornton K, Bankhurst A, et al. Partnering Urban Academic Medical Centers And Rural Primary Care Clinicians To Provide Complex Chronic Disease Care. Health Aff [Internet]. 2011 Jun 1 [cited 2018 Apr 18];30(6):1176-84. Available from: http://www.ncbi.nlm.nih.gov/pubmed/21596757 